\title{
Experiência didática com o aplicativo Euclidea
}

\author{
Carlos Magno Martins Cosme(D)
}

\begin{abstract}
Resumo
Neste artigo é compartilhada uma Experiência Didática (ED) com o aplicativo Euclidea, desenvolvida em uma turma do Mestrado Profissional em Rede Nacional Profmat do Cefet-MG, ao longo do segundo semestre de 2019, na disciplina Geometria. O aplicativo é um jogo para smartphone e computador em que o jogador resolve problemas geométricos por construção com régua e compasso. Ao fim do semestre, com a atividade encerrada, os alunos foram convidados a responder um questionário sobre a ED. Com base nas respostas obtidas e nas observações que foram sendo acumuladas ao longo do semestre, o artigo discute as implicações para o aprendizado e para a experiência didática dos estudantes que participaram da ED, bem como faz alguns apontamentos de como a atividade pode ser levada para a sala de aula dos outros níveis de ensino.
\end{abstract}

Palavras-chave: Geometria Plana. Euclidea. Construção Geométrica. Régua. Compasso.

\section{Abstract}

In this article is shared a Didactic Experience (DE) with the application Euclidea, developed in a class of Profmat/Cefet-MG, during the second semester of 2019, in the discipline Geometry. The application is a game for smartphone and computer in which the player solves geometric problems by building with a ruler and compass. At the end of the semester, with the activity closed, students were asked to answer a questionnaire about DE. Based on the answers obtained and the observations that have been accumulated throughout the semester, the article discusses the implications for the learning and didactic experience of the students who participated in the $\mathrm{DE}$, as well as making some notes on how the activity can be carried out to classroom at other levels of education.

Keywords: Plane Geometry. Euclidea. Geometric Construction. Ruler. Compass.

\section{Introdução}

Com a popularização dos smartphones em curso nos últimos anos, a educação tem diante de si um grande desafio, uma vez que é cada vez mais difícil a não utilização desses dispositivos eletrônicos pelos estudantes em uma grande parte de nossos estabelecimentos de ensino. Nesse contexto, cabe ao educador decidir utilizar ou não a ferramenta em sala de aula. Seja qual for a decisão, há uma série de questões subjacentes que devem ser abordadas e avaliadas, que não serão discutidas aqui. O leitor interessado nesse tema pode encontrar uma rica discussão em [5, 6]. Entretanto, uma vez que se opte pela utilização, como aproveitar o potencial desses dispositivos a favor do ensino é 
uma questão crucial para os educadores, apontada por inúmeros estudos, como as "Diretrizes de políticas para a aprendizagem móvel', da Unesco [4].

Dentre as várias formas de se explorar o potencial desses aparelhos, provavelmente o acesso à informação via internet é o mais difundido. Isso pode ser feito acessando artigos e livros, visitando um museu ou laboratório de pesquisa, utilizando um software, dentre tantas outras formas de conteúdo online disponível. Uma outra forma de exploração é a utilização de jogos eletrônicos, $[2,3]$. É nesse contexto que se insere esse artigo ao descrever a utilização do aplicativo $(A P P)$ Euclidea nas atividades didáticas da disciplina Geometria, cursada no segundo semestre de 2019, por uma turma do Profmat-Cefet/MG. O principal objetivo da ED foi explorar de forma não usual, através de um jogo, os conceitos de geometria plana. Além de contribuir com a formação matemática dos alunos, a atividade também serviu para mostrá-lhes uma ferramenta que pode ser levada para as suas salas de aula de matemática, uma vez que os alunos que participaram da atividade são também professores, e foco principal do Profmat é a formação docente.

A utilização do $A P P$ permitiu aos estudantes explorarem várias possibilidades de construções geométricas para um mesmo problema, sempre com o objetivo de encontrar as soluções solicitadas pelo jogo. Posteriormente, essas construções foram exploradas do ponto de vista teórico, sendo solicitado aos alunos que demonstrassem que tais construções efetivamente resolviam o desafio proposto, exercitando os elementos apreendidos da disciplina que estavam cursando.

No que segue, o texto desenvolve-se da seguinte forma: na Seção 2, o aplicativo é descrito, bem como a forma do jogo. Na Seção 3, a ED e seus objetivos são apresentados e, na seção seguinte, são mostrados alguns dos problemas abordados da ED, com as respectivas soluções apresentadas pelos alunos. Na Seção 5, são discutidas algumas questões relativas à ED, abrindo espaço para os apontamentos que os alunos fizeram no questionário sobre a experiência, e, na Seção 6, são apresentadas as conclusões do artigo e alguns apontamentos futuros.

\section{O Aplicativo}

Nessa Seção será feita uma apresentação não minuciosa do APP Euclidea. Para o leitor interessado em uma descrição completa do jogo recomenda-se a página online do APP Euclidea [7], bem como a Dissertação de Mestrado do Profmat-UFC intitulada Construções Geométricas Utilizando o Aplicativo Euclidea de Souza Filho [1].

Euclidea é um jogo eletrônico de desafios matemáticos envolvendo construções geométricas planas com régua e compasso. A Figura 1 mostra sua tela inicial. O APP foi desenvolvido e lançado pela desenvolvedora HIL - Horis International Limited [8] - em 2016, está disponível gratuitamente para as plataformas Android e $i O S$, além de poder ser jogado diretamente no computador. É um dentre vários jogos de desafios matemáticos da empresa. O leitor interessado encontrará a lista completa dos aplicativos na própria página do Euclidea [7]. 
Figura 1: Tela inicial do $A P P$.

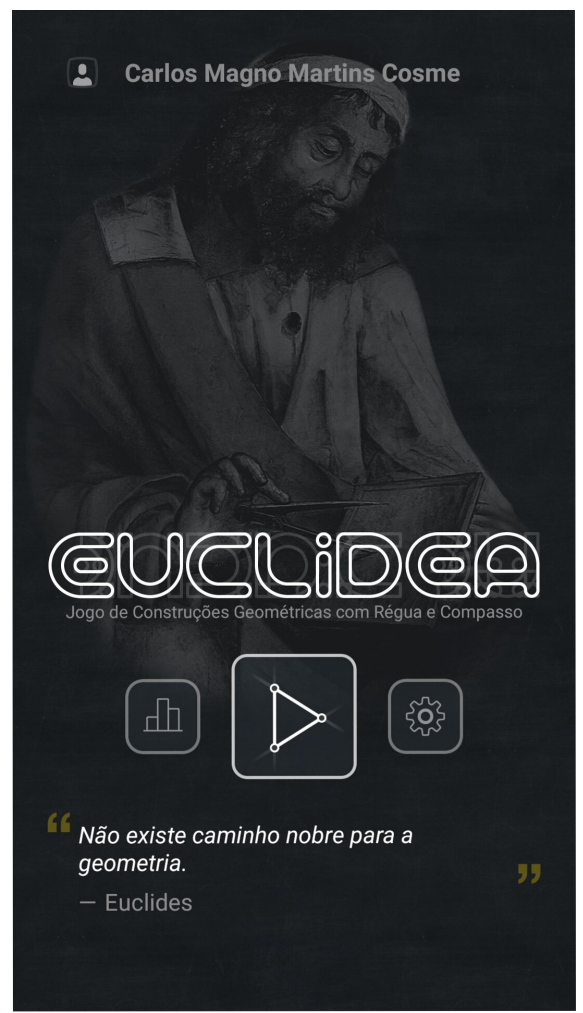

Fonte: APP Euclidea.

\subsection{As Fases do Jogo}

Bem ao estilo de icônicos jogos eletrônicos como Super Mario Bros e Sonic, Euclidea é um jogo dividido em fases, cada uma delas constituída de vários desafios a serem superados. Nesse caso, desafios bem diferentes dos jogos eletrônicos comuns, por se tratar de um problema geométrico de construção com régua e compasso. No total são 15 fases, enumeradas pelas letras gregas $\alpha, \beta, \gamma, \delta, \epsilon, \zeta, \eta, \theta, \iota, \kappa, \lambda, \mu, v, \xi$ e o (ômicron), sendo cada uma delas composta por entre 7 e 10 problemas. A Figura 2 mostra todas as fases do jogo, enquanto a Figura 3 mostra os problemas propostos para a fase inicial $\alpha$. O nível de dificuldade dos problemas propostos aumenta à medida que se avança nas fases. Em cada uma das fases, o nível de dificuldade também é gradativo, inciando com problemas mais simples e avançando para situações mais complexas. 
Figura 2: Montagem com todas as fases do $A P P$.
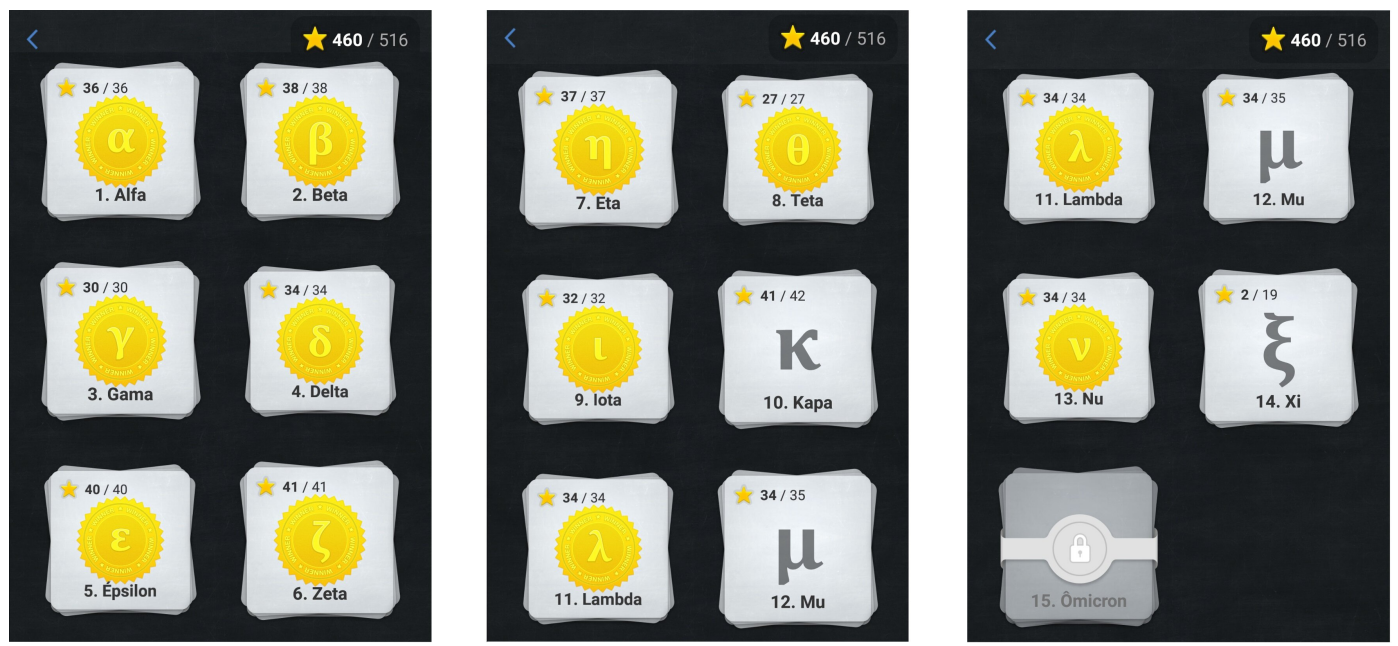

Fonte: APP Euclidea/Autor..

Além dos problemas propostos, cada fase traz alguns tutoriais sobre as ferramentas de construção geométrica disponíveis a partir daquele nível do jogo. Isso pode ser visto na Figura 3, que apresenta os tutoriais para a interseção de dois elementos e para a construção da mediatriz de dois pontos.

Figura 3: Montagem com todos os problemas da fase $\alpha$.
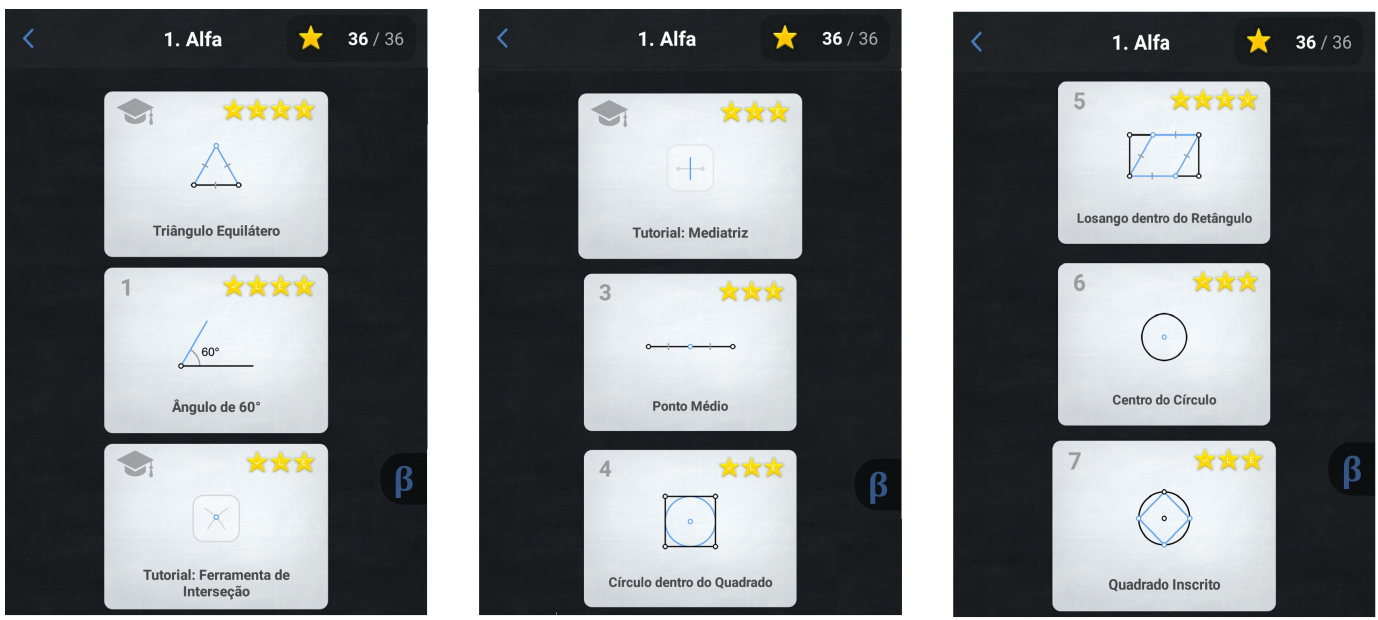

Fonte: APP Euclidea/Autor.

A evolução no jogo dá-se pela completa resolução de todos os problemas da fase, conquistando o número total de estrelas em cada problema do nível. A contagem das estrelas será discutida na próxima seção. O APP dá ao jogador a opção de avançar de fase sem conquistar todas as estrelas, mediante a compra do pacote para avançar de nível. Cada problema conta com dicas para sua resolução e um histórico das tentativas de resolução realizadas. 


\subsection{Como Jogar?!}

Como já foi dito, Euclidea é um jogo de construção geométrica com régua e compasso. Portanto, seu primeiro objetivo é resolver um determinado problema. Mas não somente isso. Cada solução é avaliada de duas formas, de acordo com o tipo de construção empregada. O tipo $L$, para linhas retas e/ou curvas, como a reta ligando dois pontos, a mediatriz de 2 pontos, um círculo etc. Nesse caso, esses elementos são ferramentas de construção disponíveis no jogo, sendo que o conjunto inicial consiste de reta e círculo. O segundo tipo de construção, $E$, para construções elementares feitas diretamente com régua e compasso. Além disso, uma determinada construção pode levar a duas soluções do mesmo problema. Isso também será contabilizado para a pontuação final da resolução do desafio.

Assim, o objetivo do jogo pode ser entendido da seguinte forma: 1 - resolver o problema; 2 - resolver o problema com um número mínimo de construções $L$ e $E$; 3 - caso seja possível, encontrar todas as variações de solução que uma mesma construção pode dar. Em algumas situações, uma mesma construção é capaz de obter a solução com o número mínimo $L$ e $E$. Mas a situação mais comum no jogo é aquela em que duas construções sejam necessárias, uma para cada objetivo. O jogador recebe uma estrela para cada subobjetivo alcançado e a tarefa estará completamente respondida se todas as estrelas do problema, veja Figura 4, forem obtidas.

Figura 4: As estrelas que servem como pontuação do jogo.

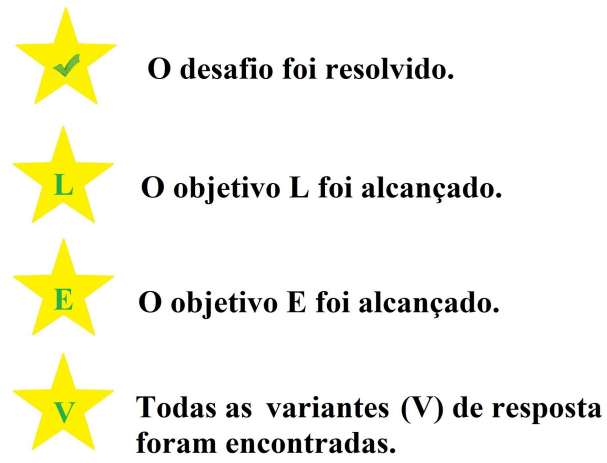

Fonte: Autor.

Vejamos, então, um típico problema do $A P P$ para entender sua dinâmica. Será considerado o problema 5 do nível inicial $\alpha$, denotado por $\mathrm{P}-\alpha .5$. Ele consiste em inscrever um paralelogramo num retângulo, de modo que os polígonos compartilhem uma diagonal. A Figura 5a mostra a tela inicial do problema. Nela chama-se a atenção para o retângulo inicial onde será construído o paralelogramo e outros três elementos apontados pelas setas enumeradas. A seta 1 indica o elemento onde se deve clicar para obter a descrição do problema. Ao fazê-lo, mostra-se a Figura 5b. Esse elemento ainda traz a informação de qual é a quantidade de movimentos mínima de tipo $L$ e $E$ ( $3 L 5 E$ nesse exemplo) para o problema. A seta 2 aponta para os comandos que o jogador utiliza para realizar as construções. Da esquerda para direita temos as seguintes ferramentas de construção: mover, ponto, reta/segmento, círculo, mediatriz e interseção. Ao clicar sobre o ícone, a ferramenta é selecionada para uso. A utilização das ferramentas mover, ponto e interseção não são contabilizadas na contagem do jogo. A construção de uma reta ou de um círculo contam $1 L$ e $1 E$, enquanto uma mediatriz conta $1 L$ e $3 E$. À medida que se avança nas fases do jogo, outras 
ferramentas vão sendo liberadas, cada uma com sua contagem. Por fim, ainda em referência à Figura 5a, a terceira seta indica um menu contendo diversas opções importantes que veremos mais à frente.

Figura 5: Telas do problema $\mathrm{P}-\alpha .5$.

(a) Tela inicial do problema.

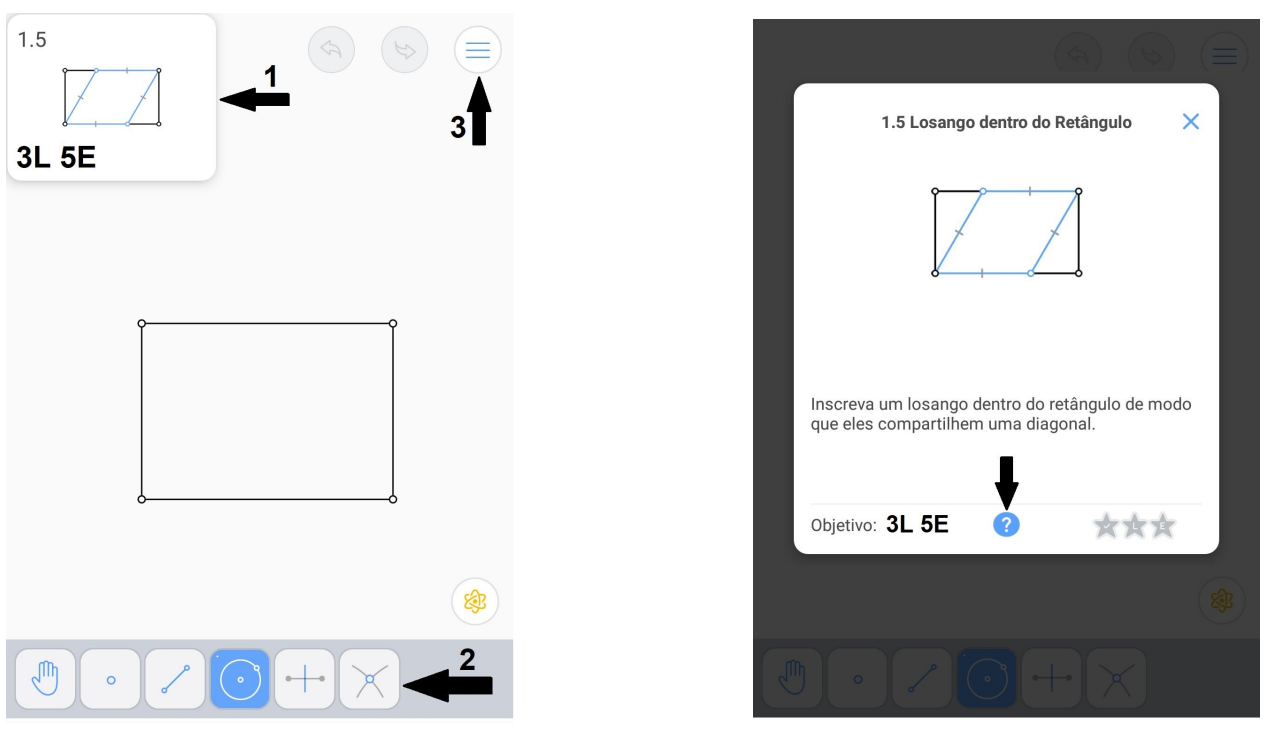

Fonte: $A P P /$ Autor.

Voltando a atenção para a Figura 5b, o botão com a interrogação, indicado pela seta, traz as definições matemáticas referentes ao problema proposto. Ao clicar sobre ele é mostrada a tela da Figura 6a. Nela temos uma lista de links para as definições matemáticas necessárias para o problema. A Figura 6b mostra a tela com a definição para os polígonos inscritos. Aqui é importante ressaltar que, do ponto de vista didático, isso mostra a preocupação dos desenvolvedores para o aspecto ligado ao aprendizado que o aluno pode ter ao jogar.

Retornando à Figura 5a, a terceira seta, no canto superior direito, aponta para o menu do aplicativo dedicado ao problema em resolução. Ao clicar sobre ele, são mostradas as opções contidas na Figura 7a. Nele, destacamos os links para o histórico de soluções anteriormente dadas para o problema, sempre disponível para o jogador, e para as dicas que podem ser obtidas para auxiliar a resolução. Esse item possui um dispositivo que impede que mais de uma dica seja obtida num intervalo de tempo de 1 hora. Caso o jogador deseje, pode comprar acesso ilimitado às dicas. As telas do Histórico e de Dicas são mostradas nas Figuras 7b e 7c.

Por fim, uma vez que o jogador inicie as suas tentativas de solução, ele pode consultar qual a figura geométrica objetivo do problema clicando sobre o elemento indicado pela seta na Figura 8a. Na tela exibida, o paralelogramo solução é destacado em amarelo. Na Figura 8b é mostrada a tela com a solução dada pelo jogador. Nesse problema, com uma única solução foi possível atingir os dois objetivos $3 L$ e $2 E$, embora possam ser obtidas soluções intermediárias que cumpram um e não o outro. Ainda nessa figura, atente-se para a contagem que aparece logo acima do menu de 
Figura 6: Telas do problema $\mathrm{P}-\alpha .5$.

(a) Definições matemáticas para o problema.

\begin{tabular}{l}
\multicolumn{1}{c}{ Informações } \\
Glossário \\
\hline Polígono Inscrito \\
\hline Losango \\
\hline Retângulo \\
\hline Diagonal \\
\hline Ajuda \\
\hline FAQ \\
\hline
\end{tabular}

(b) Definição de polígono inscrito.

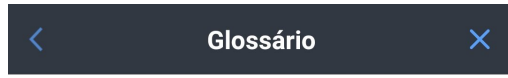

Polígono Inscrito
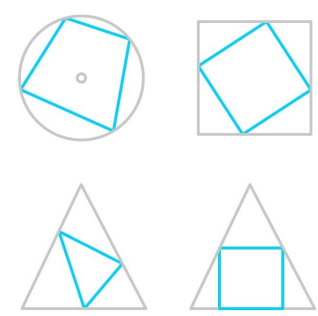

Um polígono é inscrito em uma figura (um círculo ou outro polígono) se todos os seus vértices ficam sobre a figura.

Fonte: $A P P$ /Autor.

ferramentas, indicado pela seta. Este contador é atualizado a cada nova construção que o jogador introduz. Finalmente, a Figura 8c exibe as duas variantes possíveis para a solução. Na Seção 4 nós voltaremos a abordar esse problema exibindo o passo a passo para a sua solução.

\section{Descrição da ED com o $A P P$ Euclidea}

Nesta seção será descrita a atividade desenvolvida na disciplina Geometria do Profmat/Cefet-MG, ministrada no segundo semestre de 2019, envolvendo o APP Euclidea. O objetivo é dar a outros professores de Geometria um insight de como introduzir o uso de smartphones e jogos eletrônicos nessa disciplina, seja ela ministrada no ensino básico, superior ou, até mesmo, na pós-graduação, como foi o nosso caso.

A experiência consistiu em uma atividade escolar extra, valorada em $10 \%$ da nota total da disciplina, que foi desenvolvida durante todo o semestre letivo. No primeiro dia de aula, os alunos foram apresentados ao APP e à forma de como jogá-lo. Puderam baixá-lo em seus smartphones e tiveram um contato inicial com o mesmo. Também nesse momento, foi descrita a forma como a atividade seria desenvolvida, ressaltando as suas três etapas: 1- Jogar; 2- Descrever e 3- Demonstrar. A seguir apresentaremos detalhadamente cada uma delas.

\subsection{Jogar}

Nessa primeira etapa, como o próprio nome diz, os alunos tiveram que jogar o jogo. Entretanto o fizeram coletivamente. O objetivo era avançar o máximo possível nas fases, resolvendo o maior número de problemas, por isso a proposta de jogo coletivo. Para essa etapa foi dado o prazo de 
Figura 7: Telas do problema P-1.5.

(a) Tela do Menu.

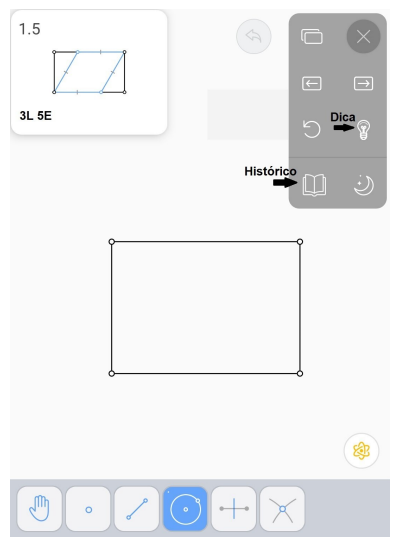

(b) Item Histórico.

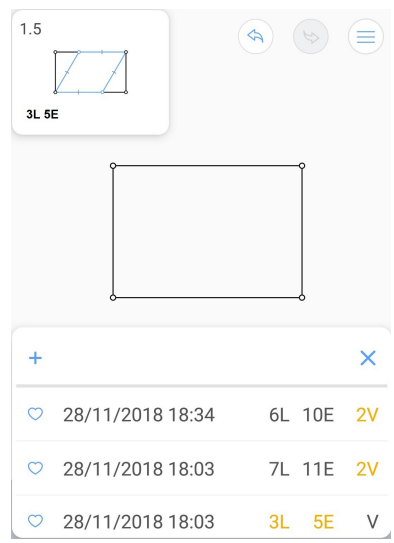

(c) Item Dicas.

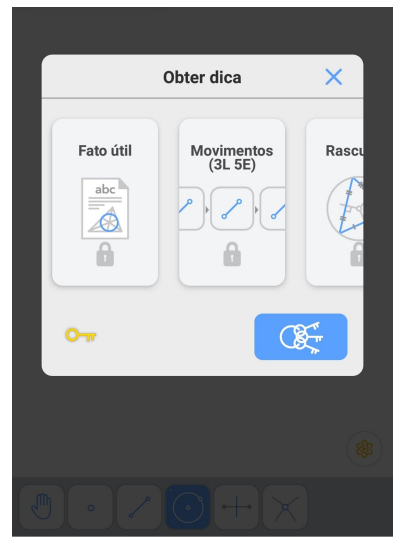

Fonte: APP / Autor.

1 (um) mês, a contar da primeira aula do semestre. Para que todos tivessem acesso ao desenvolvimento no jogo, foi criada uma conta de e-mail coletiva no Gmail por onde todos podiam logar no APP e contribuir jogando. Como alguns problemas propostos possuem construções bastante complicadas, foi aconselhado aos alunos consultarem a internet quando se deparassem com um problema que estivesse exigindo muito tempo, a fim de não emperrar o andamento da atividade.

Também foi permitido que os alunos pudessem jogar pelo computador, e isso se mostrou bastante interessante, pois jogando pelo computador, mesmo que uma fase não fosse completamente concluída, conquistando todas as estrelas, mas se todos os seus problemas fossem resolvidos, os alunos passavam a ter acesso à fase seguinte.

Ao fim dessa etapa, os alunos conseguiram resolver todos os problemas das fases $\alpha$ até à $v(1$ a 13$)$, sendo que apenas nas fases $\kappa$ e $\mu(10$ e 12) não conseguiram obter todas as estrelas, faltando uma em cada, referente à soluções múltiplas de um mesmo problema. Isto é, todos os problemas foram resolvidos, atingindo os objetivos mínimos $L$ e $E$. Ainda resolveram alguns poucos problemas da fase $\xi(14)$ e não conseguiram chegar à fase final o (15).

\subsection{Descrever}

Nas etapas subsequentes os alunos foram divididos em 5 grupos de 3 alunos e um com 2 alunos. Para cada um dos grupos com 3 (2) alunos foi selecionado um conjunto de 12 (8) problemas, distribuídos entre todas as fases resolvidas na etapa Jogar. Cada grupo trabalhou com pelo menos um problema de cada fase. Tais fases estenderam-se até o fim do semestre, uma vez que poderiam ser desenvolvidas concomitantemente.

A etapa Descrever consistiu em descrever o passo a passo da solução dada a cada problema selecionado para o grupo. Como cada questão poderia ter até três soluções distintas optou-se pelo seguinte esquema: para os problemas das fases 1 a 4, deveria ser descrita a solução dada para alcançar o objetivo $E$. Para os demais problemas, descreveram a solução para o objetivo $L$. Está 
Figura 8: Telas do problema $\mathrm{P}-\alpha .5$.

(a) A solução exibida pelo $A P P$. (b) A solução obtida pelo jogador.

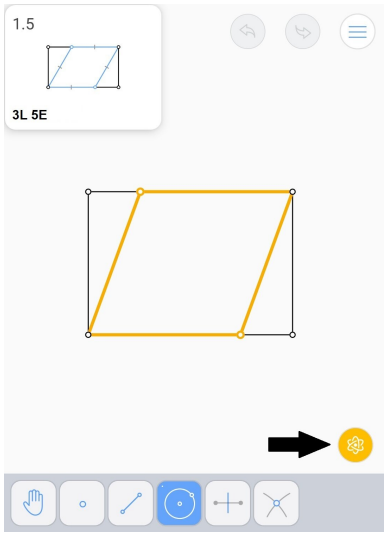

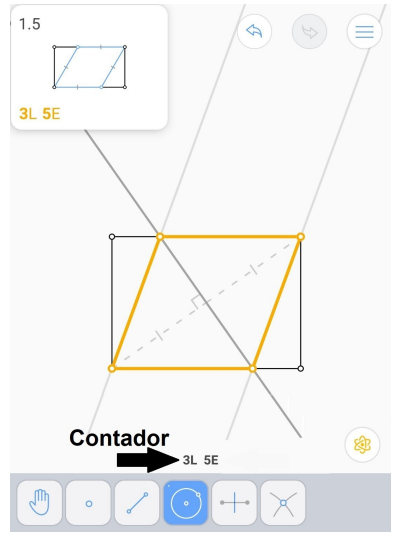

Fonte: $A P P /$ Autor. (c) Variantes da solução

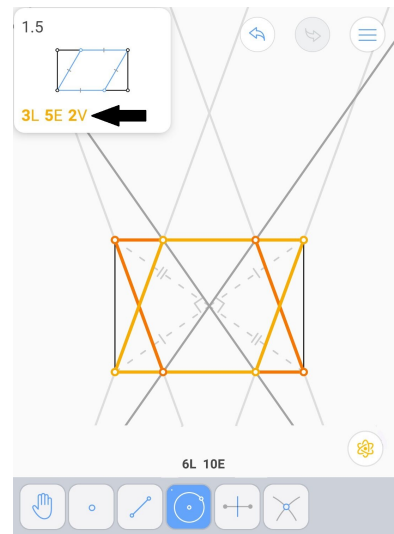

claro que a atividade seria muito mais completa se todas as soluções fossem descritas, mas isso poderia gerar uma sobrecarga indesejada nos estudantes.

Para ilustrar o que deveria ser desenvolvido nessa etapa, vamos voltar ao Problema $\mathrm{P}-\alpha .5$ abordado na seção anterior. A sequência de figuras 9a a 9c exibe graficamente a solução. Os alunos deveriam apresentar algo similar a:

1. Construa a mediatriz do segmento $\mathrm{AC}$ determinando os pontos $\mathrm{E}$ e $\mathrm{F}$ sobre os lados $\mathrm{AB}$ e $\mathrm{CD}$, respectivamente;

2. Construa o segmento AF;

3. Construa o segmento EC. O quadrilátero AECF é obtido como solução do problema. 
Figura 9: Sequência com a solução do problema $\mathrm{P}-\alpha .5$.

(a) Passo 1.

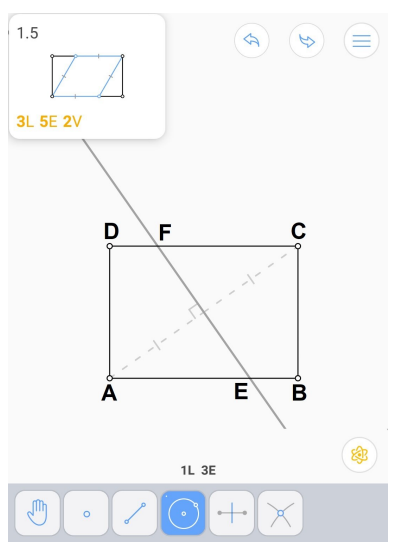

(b) Passo 2 .

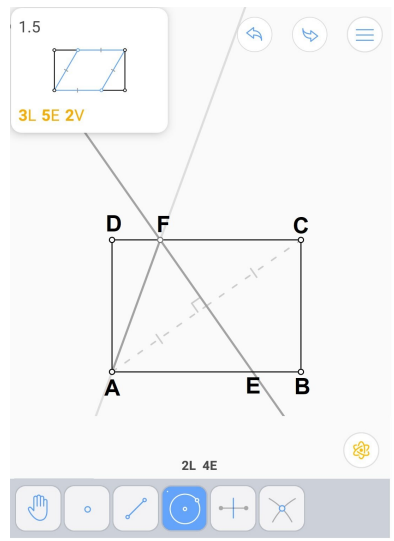

Fonte: $A P P /$ Autor. (c) Passo 3.

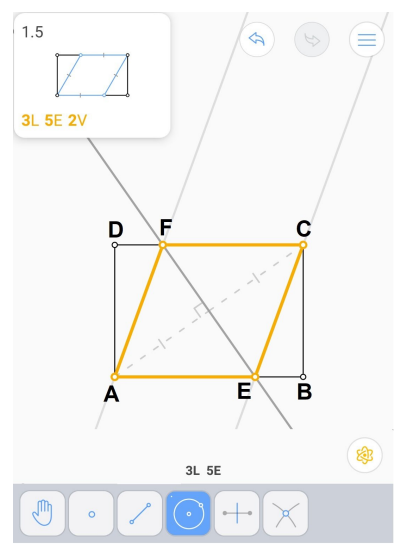

\subsection{Demonstrar}

A última etapa da atividade consistiu em demonstrar que o passo a passo descrito para a solução de cada problema, efetivamente, construía a figura solicitada. Tomando como referência o problema $\mathrm{P}-\alpha .5$, os estudantes deveriam dar uma prova como a seguinte: ,

Considere o retângulo $\mathrm{ABCD}$ e a mediatriz da diagonal $\mathrm{AC}$, que determina sobre $\mathrm{AB}$ e $\mathrm{CD}$ os pontos $\mathrm{E}$ e $\mathrm{F}$, respectivamente. Afirmamos que o quadrilátero AECF é o paralelogramo desejado. De fato, AC é diagonal comum do retângulo ABCD e do quadrilátero AECF. Como E e F estão sobre a mediatriz de AC, segue que $\mathrm{AE} \equiv \mathrm{CE}$ e $\mathrm{AF} \equiv \mathrm{CF}$, o que implica que os triângulos $\mathrm{AGE} \equiv \mathrm{CGE}$ e $\mathrm{AGF} \equiv \mathrm{CGF}$ pelo caso de congruência LLL, onde $\{\mathrm{G}\}=\mathrm{AC} \cap \mathrm{EF}$. Em particular, $\mathrm{AE} G \equiv \mathrm{CEG}$ e $\mathrm{AFG} \equiv \mathrm{CF} G$. Por outro lado, como $\mathrm{AB}$ e $\mathrm{CD}$, são paralelos, segue que $\mathrm{AE}$ e $\mathrm{CF}$ são paralelos e $\mathrm{FEA} \equiv \mathrm{EFC}$, o que nos permite concluir que $\mathrm{A} \hat{\mathrm{FE}} \equiv \mathrm{CEFF}$. Portanto, EC e AF são também paralelos e concluímos que AECF é paralelogramo.

Do ponto de vista do conteúdo matemático, essa foi a etapa que os alunos mais puderam utilizar os elementos apreendidos na disciplina, ao se deparar com a necessidade de apresentar demonstrações para um grande número de problemas. Além disso, como não estavam compartimentados em uma lista de exercícios de um certo capítulo do livro, os estudantes depararam-se com a dificuldade adicional de identificar qual o tema apropriado para a demonstração daquela propriedade.

\section{Problemas Abordados}

Nesta seção serão apresentados 4 problemas resolvidos pelos alunos. O texto será fiel, o quanto possível, ao que foi apresentado por eles na conclusão da atividade ao fim do semestre letivo. Nada será modificado em relação ao texto produzido pelos estudantes, apenas as figuras serão 
reposicionadas para melhor distribuição no corpo do artigo. Essas figuras foram obtidas, em sua maioria, dos próprios relatórios apresentados.

Problema $1(\mathrm{P}-\gamma .7)$. A Figura 10a mostra o enunciado dado pelo $A P P$.

Figura 10: Figuras mostradas na solução de $\mathrm{P}-\gamma .7$.

(a) Enunciado.

3.7 Ângulo de $45^{\circ}$

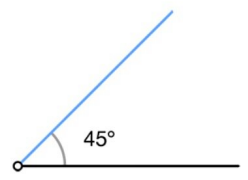

Construa um ângulo de $45^{\circ}$ com o lado indicado. (c) Construção final.

(b) Construção inicial.

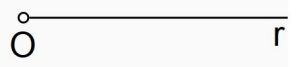

Fonte: $A P P /$ Autores.

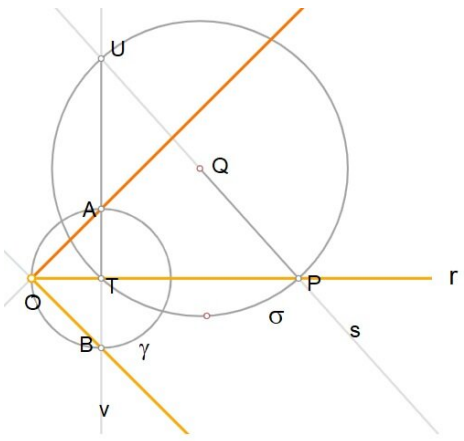

Os alunos responderam da seguinte forma:

\section{- Descrição:}

1. Trace uma circunferência $\sigma$ qualquer, de tal maneira que $\mathrm{r}$ seja secante a $\sigma \cdot \sigma \cap \mathrm{r}=\{\mathrm{T}, \mathrm{P}\}$ sendo Q o centro de $\sigma$.

2. Trace o segmento $\overline{\mathrm{QP}}$, que possui s como reta suporte.

3. Sendo $\mathrm{U} \neq \mathrm{P}$, tal que $\mathrm{UP}=\mathrm{s}$, trace o segmento $\overline{\mathrm{TU}}$, que possui v como reta suporte.

4. Trace a circunferência $\gamma=(\mathrm{T}, \overline{\mathrm{TO}})$.

5. Sendo $\gamma \cap \mathrm{v}=\{\mathrm{A}, \mathrm{B}\}$, temos que os ângulos TÔA e TÔB são ângulos de 45 .

- Demonstração: Ao traçarmos o segmento $\overline{\mathrm{TU}}$, podemos afirmar que o triângulo TUP é retângulo em T, uma vez que o ângulo UT̂P é um ângulo inscrito na circunferência $\sigma$, logo, vale metade do arco UP, que por sua vez mede 180. Logo, UT̂TP $=90$.

Ao traçarmos a segunda circunferência $\gamma$, podemos afirmar que o ângulo AÔT é inscrito na circunferência $\gamma$, e portanto é metade do ângulo central UT̂TP, ou seja, AÔT $=45$.

De maneira análoga, prova-se que BÔT $=45$.

Problema 2 ( $\mathrm{P}-\epsilon .5)$. A Figura 11 mostra o enunciado dado pelo APP. Na sequência apresentamos a solução dada pelos alunos. 
Figura 11: Problema $\mathrm{P}-\epsilon .5$.

\subsection{Cerquilha}

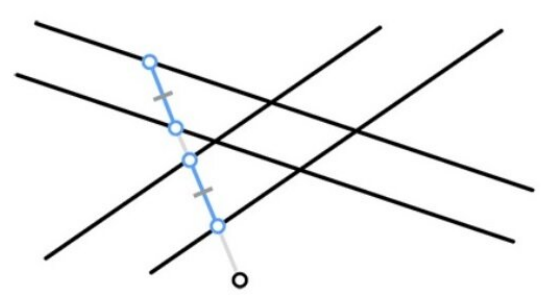

Construa uma linha passando pelo ponto indicado em que dois pares de linhas paralelas cortam segmentos de linha iguais.

Fonte: APP Euclidea.

Figura 12: Figuras mostradas na solução de $\mathrm{P}-\epsilon .5$.
(a) Passo 1.

(b) Passo 2 .

(c) Passo 3 .

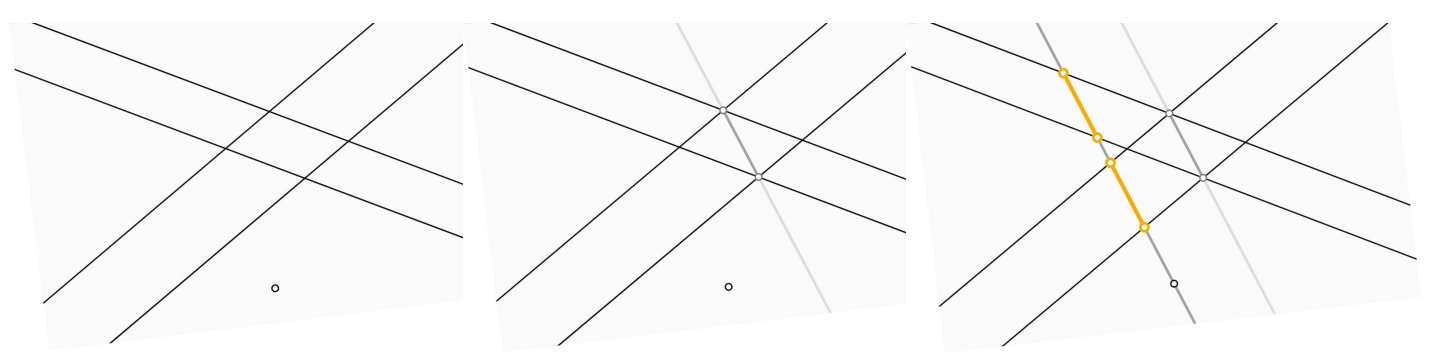

Fonte: $A P P /$ Autores.

\section{- Descrição:}

1. Sejam o ponto e os dois pares de linhas paralelas abaixo: (Figura 12a);

2. Trace a reta suporte da diagonal do quadrilátero, cujos lados sejam os segmentos determinados por cada par de linhas paralelas e uma das linhas do outro par: (Figura 12b);

3. Trace, pelo ponto dado, uma reta paralela à reta suporte da diagonal mencionada. (Figura $12 \mathrm{c})$ 
- Demonstração: Observemos, inicialmente, que o quadrilátero determinado pelos pares de retas paralelas é um paralelogramo, já que seus lados opostos são paralelos. Ao traçarmos uma linha paralela, que passa pelo ponto dado a reta suporte da diagonal construída, obtemos dois outros paralelogramos, e que possuem dois lados paralelos cuja medida é igual à diagonal construída.

Problema 3 (P - к.4). A Figura 13 traz o enunciado da questão e os passos da construção.

\section{- Descrição:}

1. Construa a circunferência $\varphi$ com centro no ponto $\mathrm{C}$ e passa pelo ponto $\mathrm{A}$;

2. Construa a circunferência $\beta$ com centro no ponto A e passa pelo ponto $\mathrm{C}$;

3. Marque os pontos $\mathrm{D}$ e $\mathrm{E}$ de interseção entre as circunferências $\varphi$ e $\beta$. Em seguida, construa a circunferência $\theta$ com centro no ponto E e que passa pelo ponto A;

4. Marque o ponto $\mathrm{G}$ de interseção entre as circunferências $\varphi$ e $\theta$. Em seguida, construa a mediatriz dos pontos $\mathrm{E}$ e $\mathrm{G}$ e marque o ponto $\mathrm{H}$ de interseção dessa mediatriz com a circunferência $\varphi$. Esse ponto $\mathrm{H}$ é a rotação de $90^{\mathrm{O}}$ do ponto $\mathrm{A}$ em relação ao ponto $\mathrm{C}$;

5. Construa a circunferência $\alpha$ com centro no ponto $\mathrm{C}$ e passando pelo ponto B;

6. Construa a circunferência $\omega$ com centro no ponto B e passando pelo ponto C;

7. Marque os pontos $\mathrm{K}$ e $\mathrm{J}$ de interseção entre as circunferências $\beta$ e $\alpha$. Construa a circunferência $\lambda$ com centro no ponto $\mathrm{K}$ e que passa pelo ponto $\mathrm{B}$;

8. Agora marque o ponto $\mathrm{M}$ de interseção entre as circunferências $\lambda$ e $\alpha$, em seguida, construa a mediatriz do segmento KM e marque o ponto $\mathrm{N}$, que é a interseção dessa mediatriz com a circunferência $\lambda$. O ponto $\mathrm{N}$ é a rotação de $90^{0}$ do ponto $\mathrm{B}$ em relação ao ponto C. Logo, o segmento HN é a rotação de $90^{\underline{0}}$ do segmento $\mathrm{AB}$ em relação ao ponto $\mathrm{C}$.

- Demonstração: Construa a circunferência $\varphi$ com centro no ponto $\mathrm{C}$ e passando pelo ponto A. Construa a circunferência $\beta$ com centro no ponto A e passando pelo ponto C. Marque os pontos $\mathrm{D}$ e $\mathrm{E}$ de interseção entre as circunferências $\varphi$ e $\beta$. O triângulo ACE é equilátero, logo, o ponto E representa a rotação de 60 do ponto A em relação ao ponto C. Em seguida, construa a circunferência $\theta$ com centro no ponto E e que passa pelo ponto A. Marque o ponto $\mathrm{G}$ de interseção entre as circunferências $\varphi$ e $\theta$. O triângulo ECG é equilátero, logo, o ponto G representa a rotação de $120^{0}$ do ponto A em relação ao ponto C. Em seguida construa a mediatriz dos pontos E e $\mathrm{G}$ e marque o ponto $\mathrm{H}$ de interseção dessa mediatriz com a circunferência $\varphi$. Esse ponto $\mathrm{H}$ é a rotação de $90^{\circ}$ do ponto A em relação ao ponto C. Analogamente, repita o procedimento acima para o ponto $\mathrm{B}$ em relação ao ponto $\mathrm{C}$; tem-se ai o ponto $\mathrm{N}$, que representa a rotação do ponto $\mathrm{B}$ em relação ao ponto $\mathrm{C}$. Ligando-se os pontos $\mathrm{H}$ e $\mathrm{N}$, temos a rotação de $90^{\mathrm{O}}$ do segmento $\mathrm{AB}$ em relação ao vértice $\mathrm{C}$.

Problema 4 ( $\mathrm{P}-v \cdot 6)$. O desafio é dado na Figura 14a. 
Figura 13: Imagens do problema $\mathrm{P}-\kappa .4$

(a) Enunciado do Problema.

10.4 Rotação de $90^{\circ} \quad \times$

$$
\int_{0}^{\circ 90^{\circ}}
$$

Gire o segmento de linha $90^{\circ}$ no sentido anti-horário em torno do ponto indicado.

(d) Passo 3.

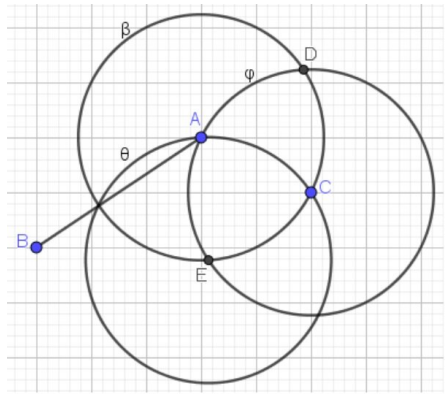

(g) Passo 6.

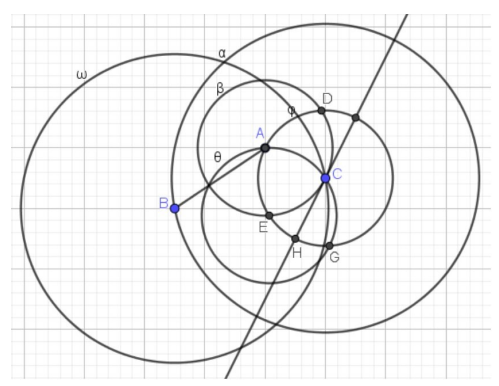

(b) Passo 1.

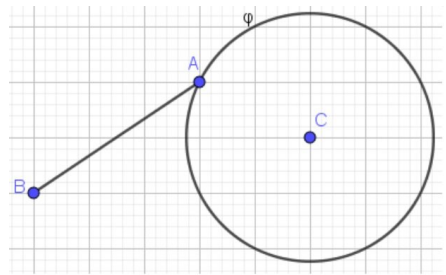

(e) Passo 4.

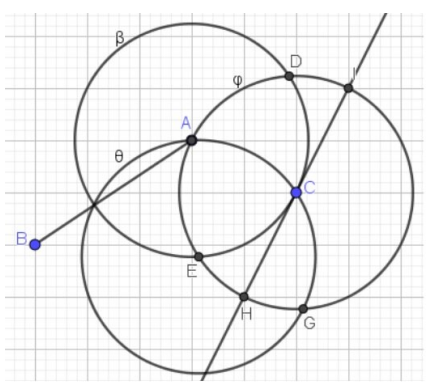

(h) Passo 7.

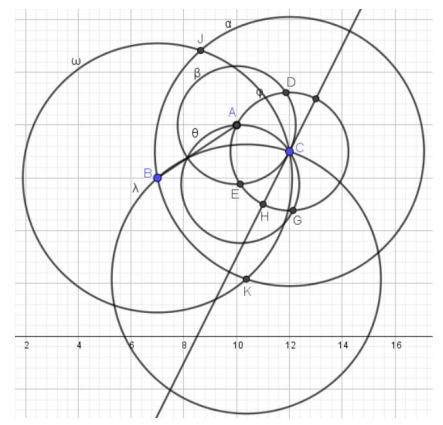

(c) Passo 2.

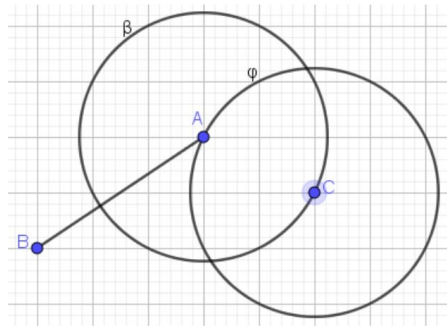

(f) Passo 5 .

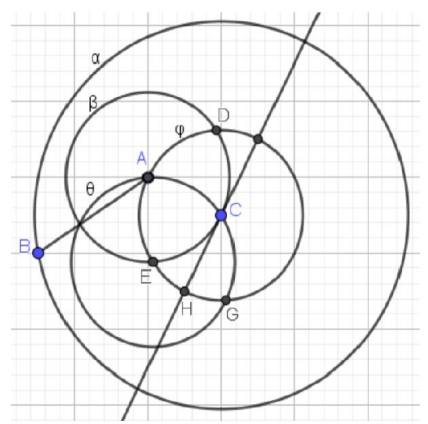

(i) Passo 8

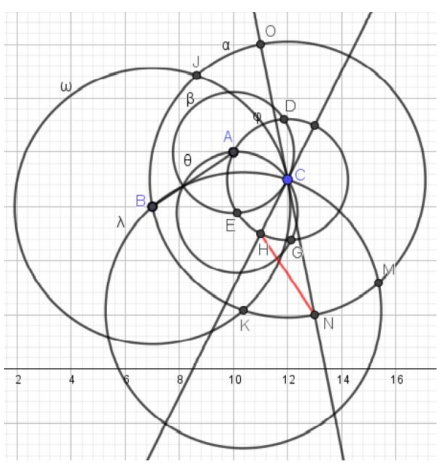

Fonte: $A P P /$ Autores. 
Figura 14: Problema $\mathrm{P}-v .6$.

(a) Enunciado.

13.6 Círculo Tangente a Dois Pontos e Tangente à Linha

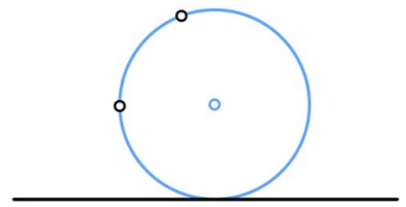

Construa um círculo que passe pelos dois pontos indicados e seja tangente ao círculo indicado. (b) Solução do problema $\mathrm{P}-v \cdot 6$.

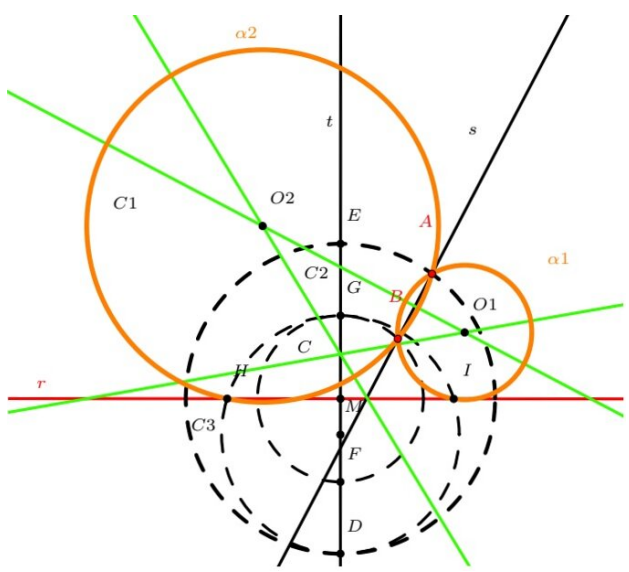

Fonte: APP / Autores.

\section{- Descrição:}

1. Trace a reta $\mathrm{s}$, definida pelos pontos $\mathrm{A}$ e $\mathrm{B}$, e seja $\mathrm{C}=\mathrm{r} \cap \mathrm{s}$. Trace $\mathrm{t}$ por $\mathrm{C}$ tal que $\mathrm{t} \perp \mathrm{r}$.

2. Trace $\mathrm{C}_{1}=\operatorname{Circ}(\mathrm{C}, \mathrm{AC})$ e $\mathrm{C}_{2}=\operatorname{Circ}(\mathrm{C}, \mathrm{BC})$ e sejam os pontos $\mathrm{D}$ e $\mathrm{G}$ em lados opostos dos que $\mathrm{r}$ determina tais que $\mathrm{D} \in \mathrm{C}_{1} \cap \mathrm{t}$ e $\mathrm{G} \in \mathrm{C}_{2} \cap \mathrm{t}$. Assim, determine $\mathrm{M}$, ponto médio de $\mathrm{DG}$, e trace $\mathrm{C}_{3}=\operatorname{Circ}(\mathrm{M}, \mathrm{MD})$, e sejam os pontos $\mathrm{H}$ e I as intersecções dessa circunferência com a reta $\mathrm{r}$.

3. Construa as mediatrizes de $\mathrm{AB}$ e $\mathrm{AI}$, e seja $\mathrm{O}_{1}$ sua intersecção, e também a mediatriz de $\mathrm{AH}$, e seja $\mathrm{O}_{2}$ sua intersecção com a mediatriz de $\mathrm{AB}$.

Afirmamos que $\mathrm{O}_{1}$ é centro da circunferência procurada, assim como $\mathrm{O}_{2}$ é centro de outra circunferência com a mesma propriedade: ambas contêm os pontos $\mathrm{A}$ e $\mathrm{B}$ e são tangentes à $\mathrm{r}$.

4. Assim, para determiná-las, basta fazer $\alpha_{1}=\operatorname{Circ}\left(\mathrm{O}_{1}, \mathrm{O}_{1} \mathrm{~A}\right)$ e $\alpha_{2}=\operatorname{Circ}\left(\mathrm{O}_{2}, \mathrm{O}_{2} \mathrm{~A}\right)$.

- Demonstração: Para provar a construção acima, precisamos de dois resultados muito usados, consequências de semelhança de triângulos, que não provaremos aqui:

Teorema 1. Seja um triângulo retângulo de altura h relativa à hipotenusa, e a e b projeções ortogonais dos catetos na hipotenusa. Então:

$$
\mathrm{a} \cdot \mathrm{b}=\mathrm{h}^{2} .
$$

Teorema 2. Seja uma $\alpha$ circunferência qualquer, uma corda AB, r uma reta tangente à circunferência no ponto I, tal que a reta por $\mathrm{AB}$ corte $\mathrm{r}$ no ponto C. Então:

$$
\overline{\mathrm{AC}} \cdot \overline{\mathrm{BC}}=\overline{\mathrm{CI}}^{2}
$$

Assim, na nossa construção temos que $\overline{\mathrm{CB}}=\overline{\mathrm{CG}}$, pois pertencem à $\mathrm{C}_{1}$, cujo centro é o ponto $\mathrm{C}$. Analogamente, $\overline{\mathrm{CA}}=\overline{\mathrm{CD}}$. Além do mais, note que $\mathrm{D}$ e $\mathrm{G}$ estão em uma reta perpendicular à reta 
r. Perceba que qualquer ponto em $\mathrm{C}_{3}$ diferente de $\mathrm{D}$ e $\mathrm{G}$, forma com esses um triângulo retângulo, pois DG é diâmetro de $\mathrm{C}_{3}$. Logo, em particular os triângulos DGI e DGH são retângulos em $\mathrm{I}$ e $\mathrm{H}$ respectivamente. Então, seja $\overline{\mathrm{CG}}=\mathrm{b}, \overline{\mathrm{CD}}=\mathrm{a}$ e $\overline{\mathrm{CH}}=\mathrm{h}$. Assim, pelo Teorema 2, temos que $\mathrm{a} \cdot \mathrm{b}=\mathrm{h}^{2}$. Portanto, pelo Teorema 2, $\mathrm{H}$ deve ser o ponto de tangência de uma circunferência tangente à reta $\mathrm{r}$ que passa por $\mathrm{A}$ e B. Analogamente, temos que I também deve ser. Assim, temos que A, B e H estão em uma mesma circunferência, assim como A, B e I, e para determiná-las basta traçar as mediatrizes de dois desses segmentos, determinando o centro de cada circunferência, $\mathrm{O}_{1}$ e $\mathrm{O}_{2}$, e depois traçando $\alpha_{1}=\operatorname{Circ}\left(\mathrm{O}_{1}, \mathrm{O}_{1} \mathrm{~A}\right)$ e $\alpha_{2}=\operatorname{Circ}\left(\mathrm{O}_{2}, \mathrm{O}_{2} \mathrm{~A}\right)$.

- Observação: Note que consideramos o caso em que a reta s, definida pelos pontos A e B, intersecta r, o que poderia não ser verdade. Ou seja, poderíamos considerar o caso em que r \|l s. Mas perceba tratar-se de um caso mais simples, pois, assim, o raio de $\alpha$ que toca $\mathrm{r}$ no ponto $\mathrm{P}$, é perpendicular a $\mathrm{AB}$. Logo, como o centro de $\alpha$ pertence à mediatriz de $\mathrm{AB}$, t, temos $\mathrm{P}=\mathrm{t} \cap \mathrm{r}$. Agora basta traçar a mediatriz de AP ou de BP, determinar sua intersecção com t, obtendo-se o centro $\mathrm{O}$ de $\alpha$, que pode ser determinada fazendo-se $\operatorname{Circ}(\mathrm{O}, \mathrm{OA})$.

\section{Discussão sobre a ED}

São muitas as questões suscitadas pela ED que merecem um olhar mais cuidadoso, e, por certo, não serão todas esgotadas nesse trabalho. A essa altura é preciso ser bastante franco com o leitor: a maioria dessas questões não eram sequer vislumbradas de início; foram surgindo à medida que a atividade foi se desenvolvendo, e evoluíram, até certo ponto, com a análise das respostas coletadas de um questionário aplicado aos alunos ao fim do semestre. Até por isso, as reflexões que serão feitas aqui podem carecer de um maior aprofundamento, quem sabe mais bem discutidas em uma dissertação do Programa e em trabalhos futuros.

Os estudantes foram convidados a responder, voluntária e anonimamente, a um questionário relacionado ao trabalho desenvolvido. Esse questionário foi apresentado via Formulários do Google e consistiu de 8 perguntas, sendo 4 com resposta em escala linear de concordância e as outras 4 em formato de resposta livre. O formulário e as respostas dadas pelos alunos podem ser consultados em: https://forms.gle/sHbFDEcLREx1XXsM8, abaixo listamos as perguntas.

1. Você considera que a atividade foi válida para o seu aprendizado na disciplina?

Resposta: de 1 (Contribuiu em nada) a 5 (Sim, foi muito válida)

2. Você considera que a atividade foi válida para a sua prática em sala de aula como docente?

Resposta: de 1 (Contribuiu em nada) a 5 (Sim, foi muito válida)

3. Como você classifica o grau de dificuldade da atividade?

Resposta: de 1 (Muito fácil) a 5 (Muito difícil)

4. Você considera utilizar o aplicativo como ferramenta didática em sua prática docente?

Resposta: de 1 (Em hipótese alguma) a 5 (Com toda certeza)

5. Relativo à questão anterior, caso considere utilizar o aplicativo com seus alunos, que ajustes e cuidados deveriam ser tomados para a atividade?

Resposta livre. 
6. Em sua opinião, qual o aspecto mais negativo sobre a atividade? Resposta livre.

7. Em sua opinião, qual o aspecto mais positivo sobre a atividade? Resposta livre.

8. De maneira geral, qual a sua avaliação sobre a atividade?

Resposta livre.

Ao fim do semestre, 15 alunos concluíram a disciplina, e, desses, 12 responderam ao questionário. $\mathrm{Na}$ sequência as respostas dadas serão analisadas, ao mesmo tempo que serão tecidas algumas considerações.

\subsection{Análise das Respostas do Questionário}

Começando pelas 4 primeiras questões, a Figura 15 apresenta as suas respostas num único gráfico de barras. A primeira delas, sobre o quão positiva foi a atividade para o aprendizado, traz um resultado muito satisfatório, pois a totalidade das respostas atribui pontuação maior que ou igual a 4, sendo que 9 alunos pontuaram em 5. Se os dados da Questão 1 forem interpretados em conjunto com a Questão 3, sobre a dificuldade da atividade, vê-se que os alunos tiveram que se empenhar para superar um trabalho que a maioria (75\%) considerou bastante difícil. Ou seja, foi realmente necessário um esforço de estudo para cumprir a tarefa e isso é um aspecto muito positivo, pois o ganho de conhecimento foi efetivamente conquistado devido a isso. Ainda sobre a dificuldade apontada na Questão 3, nota-se que ela é de dois tipos: a dificuldade do jogo, de se obter as soluções solicitadas, e a dificuldade teórica presente nas duas etapas finais. Voltaremos a essa discussão mais à frente.

Também o par de Questões 2 e 4 pode ser analisado em conjunto, uma vez que objetivaram entender a percepção dos estudantes sobre como a ED implicava sua prática em sala de aula. Essa reflexão fará mais sentido se a atividade foi/for proposta numa turma como a do Profmat ou em uma turma de graduação em licenciatura em matemática, por exemplo. Sobre a análise das respostas, aqui observamos um maior espalhamento, sendo que 1/3 dos estudantes não consideraram a experiência tão significativa para sua prática como professor. Embora nenhum aluno tenha dito que a atividade foi totalmente inútil nesse sentido, um alerta é dado. Para que a atividade atinja o objetivo de dar ao aluno-professor subsídios para a sua prática docente, algo precisa ser modificado, melhorado. O foco da ED não pode ser apenas o conteúdo matemático. 
Figura 15: Respostas às Questões 1 a 4.

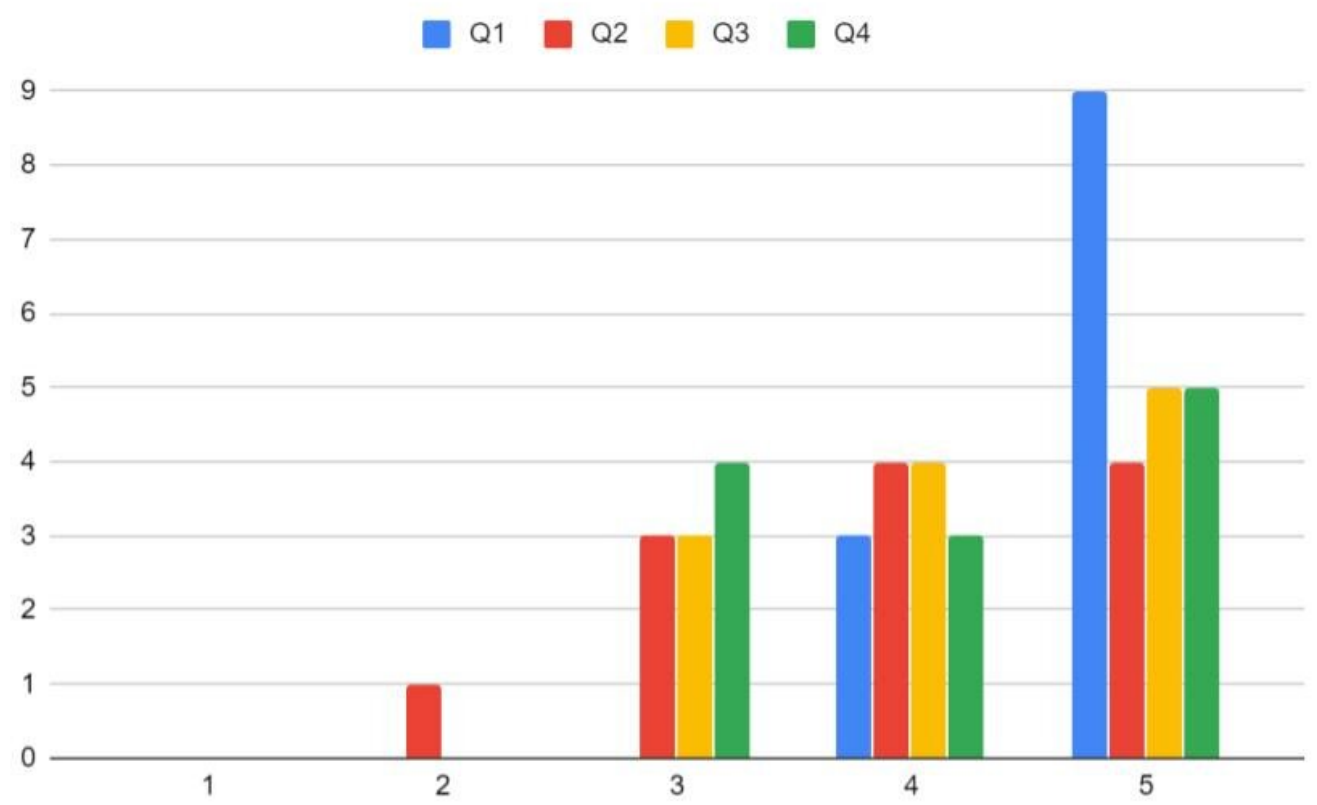

Fonte: Autor.

Chegando às questões de resposta aberta, a de número 5 ainda explora o aspecto da atividade relacionada à prática docente dos alunos da turma. Observa-se, da maioria das respostas, a percepção de que a atividade deve ser remodelada para sua aplicação em turmas da Educação Básica, restringindo-se a problemas mais simples, previamente escolhidos e que estejam de acordo com o conteúdo da série em que será trabalhada. Uma segunda percepção observada em um número significativo de respostas é referente ao aspecto prático da utilização do aplicativo, apontando para a necessidade de ser mais bem explicado como jogar.

As três últimas questões pediam uma avaliação geral da atividade, apontando seus aspectos mais positivos e negativos. Não poderiam ser mais diversas as respostas, mas em geral os alunos consideraram a atividade muito significativa para o seu aprendizado. Mas começando pelo que não foi bem, de maneira geral, os alunos apontaram aspectos negativos relacionados ao jogo em si, sendo o mais recorrente deles que vários problemas dados no $A P P$ tinham soluções muito difíceis de serem obtidas. Muitas vezes essas soluções não faziam sentido para os alunos, como no relato: "Algumas construções que você precisa praticamente adivinhar os passos devido a sua dificuldade.". Essas observações devem nortear estratégias para o desenvolvimento de novas experiências com o Euclidea, a fim de mitigar tais problemas. Por exemplo, uma melhor preparação dos alunos em relação à atividade, bem como propondo a resolução em conjunto de alguns problemas cujas construções apresentadas como solução não deixem óbvio como, efetivamente, resolvem o problema.

Outro ponto negativo apontado por um aluno foi: "Ser trabalho sem feedback". Não houve tempo para dar o retorno aos alunos sobre a atividade, principalmente por um planejamento inicial mal feito. Como já mencionado, muito da atividade foi sendo desenvolvida ao longo do semestre e, ao 
fim, já não havia tempo hábil. Sem dúvida esse foi o aspecto mais falho na ED.

Voltando-nos para o que de positivo foi apontado, felizmente a lista é grande e abrange tanto aspectos concernentes ao jogo, por ser desafiador, por seus problemas, jogabilidade e praticidade e a satisfação em resolver um problema difícil, como disse um aluno: "A alegria e o prazer ao conseguir resolver e discutir belas construções geométricas."; quanto à parte mais instrutiva da $\mathrm{ED}$, relacionada à etapa das demonstrações e também à utilização de uma ferramenta não usual para aprender/ensinar geometria, como pode ser extraído das respostas: "A utilização do jogo como alternativa para se pensar problemas de construção geométrica." e "Dinâmica na resolução, fugindo do modelo teorema, exemplo, exercício.". Todas essas observações corroboram a expectativa de que o emprego de estratégias apoiadas no uso das tecnologias que estão à disposição, de forma particular, de um jogo como Euclidea, pode ser muito benéfico para o aprendizado de certos temas abordados em sala de aula, servindo como elemento inovador e entusiasmante para os estudantes.

\subsection{E o que mais?!}

Além das observações apresentadas a partir das respostas dos alunos ao questionário, outras reflexões merecem ser abordadas nesse texto, a começar pelo fato de a ED ter se baseado em um jogo para ser desenvolvida, o que confere à atividade características peculiares. Destacam-se: a capacidade de atrair a atenção dos alunos; a competitividade inerente ao jogo e os diferentes tipos de dificuldade encontradas.

Para uma geração de alunos que vem tendo acesso aos meios eletrônicos desde muito cedo, a perspectiva de aprender matemática utilizando um aplicativo para smartphone deve ser, no mínimo, instigante. Não cabe, nesse estágio, fazer afirmações cabais sobre esse elemento de reflexão, mas se mesmo para os estudantes que participaram da ED, todos adultos, em sua maioria com idade próxima ou acima dos 25 anos, a experiência trouxe-lhes o sentimento da novidade, do instigante, da provocação, pode-se projetar uma expectativa muito positiva para intervenções desse tipo nas salas de aula do ensino básico ou da graduação.

$\mathrm{Na}$ ED, a competitividade, não necessariamente entre um jogador e outro, algo intrínseco ao ato de jogar, foi substituída pela colaboração entre todos os alunos da turma, uma vez que na etapa inicial da ED, os alunos jogaram juntos em uma mesma conta, com o objetivo de avançar o máximo possível nos níveis. Feita essa escolha, algo que se deve ter em mente é que algum aluno pode colaborar mais (talvez muito mais) que outro, e, da forma como foi conduzida a atividade, não se controlou esse elemento. Numa turma de pós-graduação isso tende a ser uma questão menor, mas ao se pensar em levar a experiência a outros níveis de ensino, sem dúvida, deve-se remodelar a atividade, incluindo em alguma medida o aspecto da competitividade como fator de estímulo e controle para a participação efetiva de todos, sendo isso uma característica natural do jogo em si, facilmente implementável.

Ainda relacionado ao jogo/ED, um tema que chama a atenção é seu grau de dificuldade. Várias respostas do questionário colocam essa questão em destaque, como já abordado na seção anterior, mas é importante avançar um pouco na reflexão. Primeiro entendendo que há aqui uma certa confusão, pois, como já foi dito, há dois tipos de dificuldades a se considerar: a dificuldade do jogo, no que diz respeito à obtenção da solução; e a dificuldade teórica, proposta pela atividade, em que se deve demonstrar que a construção geométrica obtida, efetivamente é a solução. Compreender cada uma delas é essencial para aqueles que estejam interessados em aplicar essa atividade em sua turma. Para um professor do ensino básico, modular os problemas, escolhendo-os de acordo 
com o conhecimento de geometria que seus alunos já possuem deve ser o foco principal, sendo essa estratégia mais voltada à primeira dificuldade. Em outra ponta, por exemplo, numa turma de licenciatura ou bacharelado em matemática, embora as questões ligadas à primeira dificuldade não possam ser negligenciadas, o aspecto preponderante na atividade deverá estar ligado à segunda.

Outro fato que merece discussão é que, ao resolver os problemas propostos pelo $A P P$, o jogador depara-se com a necessidade de encontrar não uma única solução, mas várias. Em determinados casos, obrigatoriamente, devem ser encontradas pelo menos 3 soluções. Não é necessário dizer que, do ponto de vista do aprendizado, lidar com várias soluções para um mesmo problema é extremamente relevante, e, no contexto da utilização do $A P P$ como ferramenta didática, isso é implementado de maneira muito natural, uma vez que faz parte do jogo em si. Essa característica ainda se relaciona com outro aspecto teórico importante, que é o de lidar com as demostrações dessas propriedades. Embora nos tenhamos restringido a exigir dos alunos a demostração de apenas uma das construções, a ED permite que o aluno seja levado a exercitar as várias demostrações possíveis para o mesmo problema. Isso pode ser explorado regrando-se os problemas abordados, em todos os níveis de ensino, dando aos estudantes a oportunidade de amadurecer essa competência precocemente.

Por fim, cumpre observar que o APP Euclidea vem se somar, como ferramenta de ensino de geometria, a outros softwares já consolidados na literatura, como o GeoGebra, [9]. Um vislumbre interessante seria resolver os mesmo problemas propostos pelo APP via GeoGebra. Isso permitiria explorar as propriedades algébricas das construções e teríamos uma maneira interessantíssima de abordar os mesmos problemas do ponto de vista da Geometria Analítica. Quantas outras possibilidades!

\section{Conclusão}

A primeira coisa a ser dita nessa conclusão é que a ED foi muito positiva em vários aspectos, tanto para os estudantes, quanto para o professor. Uma oportunidade de aprendizado mútuo muito enriquecedora e valorosa. É curioso notar como uma brincadeira - foi assim que descobri o Euclidea- pôde se converter em algo tão instigante.

Embora, nas considerações inicias deste trabalho, tenha sido dito que não abordaríamos a questão do deve-se ou não utilizar o smartphone em sala de aula, tudo que foi desenvolvido até aqui é, sem dúvida, uma defesa da utilização desse tipo de tecnologia. Seria um contrassenso afirmar o contrário. É, porém, importante chamar a atenção para o fato de que, mesmo aqueles que não queiram utilizar o APP em sala de aula, podem remodelar a atividade para que seus alunos a desenvolvam em laboratórios de informática, em computadores, usando a versão para desktop.

Há que se ter em mente os pontos falhos da atividade e isso deverá nortear novas aplicações da mesma. É lugar comum dizer que, antes de inciar o trabalho, um planejamento detalhado do mesmo deva ser feito, a fim de evitar problemas como os apontados pelos estudantes. Esse planejamento deve incluir um cronograma detalhado especificando a duração de cada etapa, reservando tempo para dar retorno aos alunos. É também imprescindível fazer uma seleção das fases e problemas que serão abordados com o objetivo de adequar a atividade ao grupo e conteúdos que devam ser abordados. No entanto, pode-se optar por deixar alguns problemas como desafios extras, uma espécie de easter eegs ${ }^{1}$ a serem desvendados.

${ }^{1} \mathrm{O}$ termo easter egg significa ovo de páscoa, em inglês, mas também é o nome dado a segredos escondidos em programas, sites ou jogos eletrônicos, [10]. O termo também tem sido empregado no mundo cinematográfico, [11]. 
Ao finalizar esse texto, uma série de temas interessantes colocam-se à nossa frente para serem explorados. Quais as expectativas para a utilização do Euclidea na educação básica? Em uma turma de licenciatura em matemática como deveria ser remodelada a proposta da experiência e que resultados esperar? Como explorar o aplicativo em conjunto com o GeoGebra? Todas essas e outras questões, se bem exploradas e desenvolvidas, podem ser temas para ótimas dissertações do Profmat. Abriu-se uma pequena janela.

\section{Agradecimentos}

Um agradecimento muito especial a todos os alunos da turma Profmat/Cefet-MG 2019-02 pela participação efetiva na atividade, na resposta ao questionário e por terem sido extremamente solícitos e generosos ao permitirem o uso neste artigo das soluções apresentadas em seus relatórios finais. Agradeço também à Profa. Fernanda A. Ferreira e ao Prof. Allan R. F. Teixeira por seus valiosos apontamentos. A todos, muito obrigado.

\section{Referências}

[1] Souza Filho, J.R. Construções Geométricas Utilizando o Aplicativo Euclidea. Dissertação (Mestrado em Matemática) - Universidade Federal do Ceará, Fortaleza - CE, 2017.

[2] Fonseca, J. M. S. Jogos de Computador no Ensino de Matemática. Dissertação (Mestrado em Matemática) - Universidade Federal de Viçosa, Florestal - MG, 2018.

[3] Rodrigues, C. S. Números Aleatórios e os Jogos de Computador. Dissertação (Mestrado em Matemática) - Universidade Federal de Viçosa, Florestal - MG, 2019.

[4] Unesco. Diretrizes de políticas para a aprendizagem móvel. Paris - FR, 2013. Disponível em: 〈http://www.bibl.ita.br/UNESCO-Diretrizes.pdf〉. Acesso em: 23 de março 2020.

[5] Lopes, P. A. e Pimenta, C. C. C. "O uso do celular em sala de aula como ferramenta pedagógica: benefícios e desafios". Revista Cadernos de Estudos e Pesquisa na Educação Básica, CAp UFPE, Recife - PE, V.3, n. 1, p. 52-66, 2017.

[6] Confessor, F. I. C. Novas tecnologias: desafios e perspectivas na Educação. Brasil: Clube dos Autores, 2011.

[7] EUCLIDEA. Euclidea: Geometric Construction Puzzle. Hong Kong, 2014. Disponível em: $\langle$ https://www.euclidea.xyz/en/〉. Acesso em: 23 de março 2020.

[8] HIL. Horis International Limited. Hong Kong, 2012. Disponível em:〈http://www.hil-hk.com/〉. Acesso em: 25 de março 2020.

[9] Hohenwarter, M., et al. GeoGebra. 2017. Disponível em:〈http://www.geogebra.org〉. Acesso em: 16 de abril 2020.

[10] Coutinho, M. O que são 'easter eggs' e quais são os mais famosos do Google. Rio de Janeiro, 2013. Disponível em: 〈https://www.techtudo.com.br/noticias/noticia/2013/09/ o-que-sao-easter-eggs-e-quais-sao-os-mais-famosos-do-google.html $\rangle$. Acesso em: 16 de abril 2020.

[11] LondonEye Idiomas. O que significa o termo easter eggs?. Bauru - SP, 2019, Disponível em: 〈http://www.londoneyeidiomas.com.br/easter-eggs/〉. Acesso em: 16 de abril 2020. 
Carlos Magno Martins Cosme

Departamento de Matemática

Centro Federal de Educação Tecnológica de Minas Gerais

Cefet-MG. Av. Amazonas 7675

Belo Horizonte - MG, Brasil. 30510-000.

<cmagnomc@Cefetmg.com>

Recebido: $29 / 04 / 2020$

Publicado: 22/06/2020 